\title{
Fluxless Sn-3.5 mass\% Ag Solder Bump Flip Chip Bonding by Ultrasonic Wave
}

\author{
Soon-Min Hong ${ }^{1}$, Choon-Sik Kang ${ }^{2}$ and Jae-Pil Jung ${ }^{3}$ \\ ${ }^{1}$ Micro-joining Lab., Institute of Intelligent System, Mechatronics Center, Samsung Electronics Co. Ltd., \\ Suwon, Kyungki-Do 442-742, Korea \\ ${ }^{2}$ School of Materials Science \& Engineering, Seoul National University, Seoul 151-744, Korea \\ ${ }^{3}$ Department of Materials Science \& Engineering, University of Seoul, Seoul 130-743, Korea
}

\begin{abstract}
The ultrasonic solder bump flip chip bonding was investigated as a method of fluxless bonding. The $100 \mu \mathrm{m}$-diameter Sn-3.5 mass $\%$ Ag solder bumps were formed at 12 positions on a test $\mathrm{Si}$-die by laser ball bonding process. The test flip chip dies were bonded to a TSM-coated glass substrate on a hotplate at different bonding loads and ultrasonic power condition. The die shear strength was evaluated and fracture surfaces were examined with SEM. The Sn-Ag solder flip chip bonding was possible at lower temperature than the melting point of Sn-3.5Ag solder. The die shear strength increased with increasing bonding temperature, bonding load, and ultrasonic power. However, at excessive bonding load condition over $0.8 \mathrm{~N} /$ bump, the die shear strength decreased. The bump height decreased with increasing bonding load.
\end{abstract}

(Received December 25, 2001; Accepted April 12, 2002)

Keywords: flip chip bonding, Lead-free solder, fluxless, ultrasonic wave, solder, bump, die shear strength

\section{Introduction}

The solder bump flip chip technology, which is an ultimate way to increasing packaging density, is widely used for fine-pitch connection between high-I/O components and substrates. It has proven to be a high-yield and reliable joining technology. The application of flip chip package has been extended to optoelectronics and MEMS (Microelectromechanical system) package. ${ }^{1)}$

Figure 1 represents flip chip on glass package system. In a conventional solder bump flip chip packaging process, flux is used in two processes: solder bumping and flip chip bonding. Solder evaporation through aligned metal mask, solder alloy electroplating, stencil solder paste printing, and solder wire stud bumping are the main flip chip solder bumping techniques which are applied in current packaging industry. The evaporated, plated, or printed solder on defined UBM (Under Bump Metallurgy) patterns is usually fluxed and reflowed to get homogeneous, ball-shaped bumps.

Another process where flux is applied is flip chip bonding. In a conventional tacky flux process, flux is applied to the solder bump and the chip is place on the TSM (Top Surface Metallurgy) pad of the substrate followed by reflow.

However, especially in fine pitch flip chip package, the residual flux may exist in the region where inspection and removal of the residue are almost impossible. ${ }^{2)}$ The flux residue remaining on components after soldering process can cause corrosion of micro-circuit and give rise to long-term reliability problems. ${ }^{3)}$ Besides, the flux cleaning solvents are proved to be detrimental effect on environment. Montreal Protocol

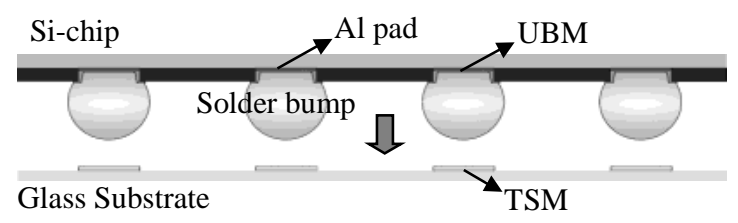

Fig. 1 Si-chip on glass flip-chip bonding system. and Kyoto Protocol are typical examples of international regulations on the use of ozone-depleting and global warming solvents and gases. Because of the environmental concerns, a manufacturer needs to find an effective replacement of flux. Therefore, fluxless flip chip soldering is becoming an active area of research.

There are some fluxless flip chip bonding processes using plasma of $\mathrm{CF}_{4}{ }^{4)}$ or $\mathrm{SF}_{6}{ }^{5)}$ gas and acid vapor process using carboxylic acid. $\left.{ }^{6}\right)$ However, the fluorine is known to be an etchant for $\mathrm{SiO}_{2}$ and $\mathrm{SiN}_{x}$ that are often used as passivation films in flip chip package. ${ }^{7)}$ The acid based technique will generate gallons of waste gas, which must undergo purification after processing.

The ultrasonic bonding can be used as one of fluxless flip chip bonding methods. Currently, thermosonic bonding is applied to the Au bump flip chip bonding, for Au bumps cannot be bonded by reflow process. ${ }^{8-14)}$

This work intended to apply the thermosonic bonding to solder bump flip chip bonding as a fluxless bonding method. Many $\mathrm{Pb}$-free solders under development have higher melting point than that of eutectic $\mathrm{Sn}-\mathrm{Pb}$ solder $\left(183^{\circ} \mathrm{C}\right)$. Thus, their reflow process temperatures are $30-40^{\circ} \mathrm{C}$ higher than that of eutectic $\mathrm{Sn}-\mathrm{Pb}$ solder. Higher process temperatures may have a severe, negative impact on component performance. ${ }^{15)}$ In this respect, ultrasonic bonding can be useful to solder flip chip devices sensitive to high operation temperature because the bonding is performed below the melting point of the solder. Thermosonic bonding of solder bump flip chip is expected to solve the problem of high reflow temperature as well as the problem of using flux. Because the thermosonic bonding is a way of boding of two bodies in solid state by ultrasonically generated friction. Therefore, solder does not have to be heated above its melting point temperature like in conventional solder flip chip bonding by reflow.

This paper reports the application of the thermosonic bonding to $100 \mu \mathrm{m}$-size $\mathrm{Sn}-3.5$ mass\% Ag solder-bump flip chip to glass substrate. The effects of the thermosonic bonding process parameters such as bonding load, substrate tempera- 


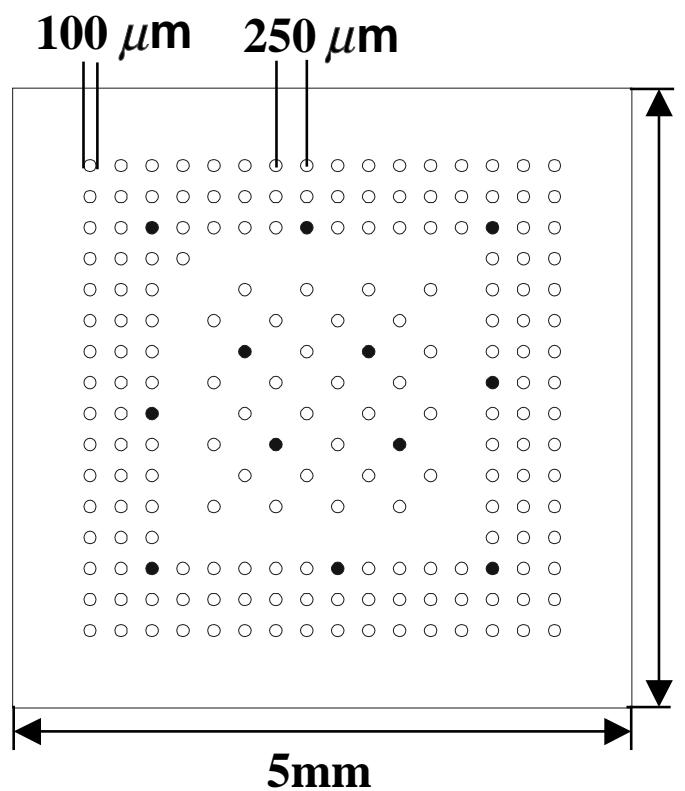

(a)

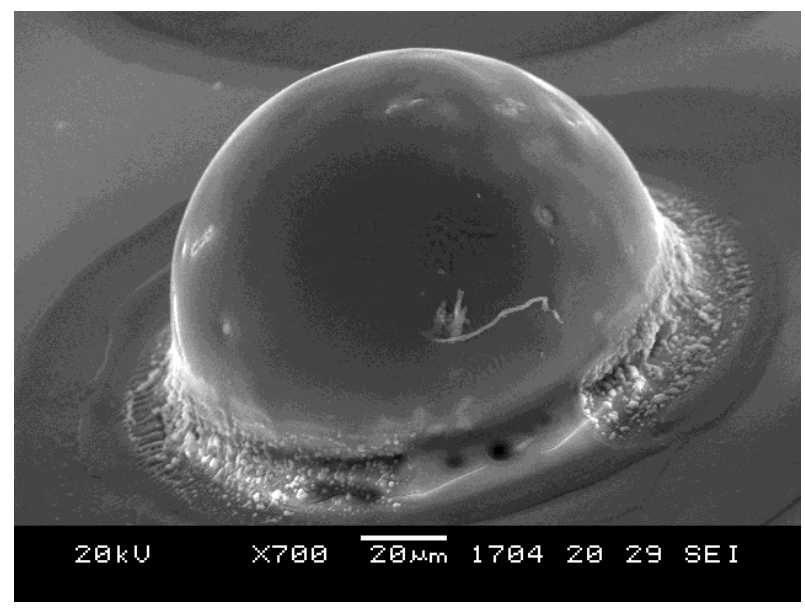

(b)

Fig. 2 Test flip chip for fluxless bonding by plasma treatment. (a) The closed circles are 12 bumps positions on Si-die for flip chip bonding. (b) A Sn-3.5 mass $\% \mathrm{Ag}$ solder bump reflowed with flux on hotplate at $250^{\circ} \mathrm{C}$ for $60 \mathrm{~s}$.

ture, and ultrasonic power on the die shear strength and bump height were studied.

\section{Experimental Procedure}

$5 \mathrm{~mm} \times 5 \mathrm{~mm}$ test $\mathrm{Si}$-dies for fluxless thermosonic bonding were fabricated by bumping 12 solder balls on defined circular UBM pattern with the diameter of $100 \mu \mathrm{m}$ as shown in Fig. 2(a). The $4 \mu \mathrm{m}-\mathrm{Cu} / 4 \mu \mathrm{m}-\mathrm{Ni} \mathrm{UBM}$ was electroplated to $\mathrm{Cr} / \mathrm{Cu}$ seed layer on Si-wafer after thick PR photolithography. The bumps were formed by laser ball bonding of $\mathrm{Sn}-3.5 \mathrm{Ag}$ solder ball with $100 \mu \mathrm{m}$ diameter. After ball bonding, the dies were reflowed on a hotplate with VOC-free flux (SF-531, Soltec.). The $\mathrm{Sn}-3.5 \mathrm{Ag}$ bumps were reflowed at $250^{\circ} \mathrm{C}$ for $60 \mathrm{~s}$. Figure 2(b) shows a Sn-3.5Ag solder bump after reflow. The height of the solder bump after reflow was about $70 \mu \mathrm{m}$ and the bump shear strength was $0.6-0.7 \mathrm{~N} / \mathrm{bump}$.

The test flip chip specimen with $\mathrm{Sn}-3.5$ mass $\% \mathrm{Ag}$ solder bumps on 12 positions was boned to a TSM-coated glass substrate. The TSM of the glass substrate was formed of $\mathrm{Cr}$ $70 \mathrm{~nm} / \mathrm{Cu} 1 \mu \mathrm{m} / \mathrm{Au} 100 \mathrm{~nm}$ metal layers deposited by E-beam evaporation. Figure 3 shows a schematic diagram of the ultrasonic bonding. The horizontal ultrasonic wave was applied with UTHE Tech. Ultrasonic generator 50G model and the transducer was UTHE Tech. 29PT piezoelectric.

The die collect was not heated, and only the hotplate was heated within temperature range of $150-200^{\circ} \mathrm{C}$. During bonding process, the bonding load to the specimen was set between $0.2-1.2 \mathrm{~N} / \mathrm{bump}$. The experimental range of ultrasonic power was set between $0-50 \mathrm{~W}$. The ultrasonic was triggered at $75 \mathrm{~s}$ after bonding process for $500 \mathrm{~ms}$.

Die shear test was performed to evaluate the bonding strength between the $\mathrm{Si}$-die and the glass substrate. The shear tool was $100 \mu \mathrm{m}$ from TSM and the shearing rate was $200 \mu \mathrm{m} / \mathrm{s}$. The bond strength per bump was calculated by di-

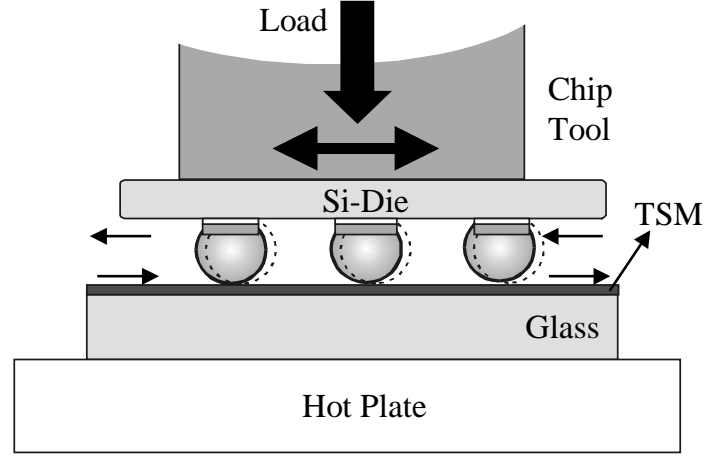

Fig. 3 A schematic diagram of a horizontal ultrasonic bonding system.

viding the value of die shear strength by 12 . After the shear test, fracture surfaces of the Si-side and glass substrate side were analyzed with SEM. The effect of bonding temperature, bonding load, and ultrasonic power on the die shear strength and bump height was estimated.

\section{Results and Discussion}

The Sn-3.5Ag solder-bump flip chip dies were bonded using ultrasonic wave to a TSM-coated glass substrate. The die shear test was performed after bonding. Figure 4 shows the die shear strength with bonding temperature at bonding load of $0.8 \mathrm{~N} /$ bump and ultrasonic power of $25 \mathrm{~W}$. The shear strength increased with proportional to bonding temperature. The die shear strength of the chip bonded by ultrasonic wave below the melting temperature of $\mathrm{Sn}-3.5 \mathrm{Ag}$ solder $\left(221^{\circ} \mathrm{C}\right)$ was quite high. Even at $150^{\circ} \mathrm{C}$, the lowest bonding temperature, the die shear strength was above $0.05 \mathrm{~N}$ per bump which is the standard strength criterion for sound flip chip solder joint. ${ }^{9)}$ Figure 5 shows the die shear strength with the bonding load at $25 \mathrm{~W}$ ultrasonic power. For all bonding tempera- 


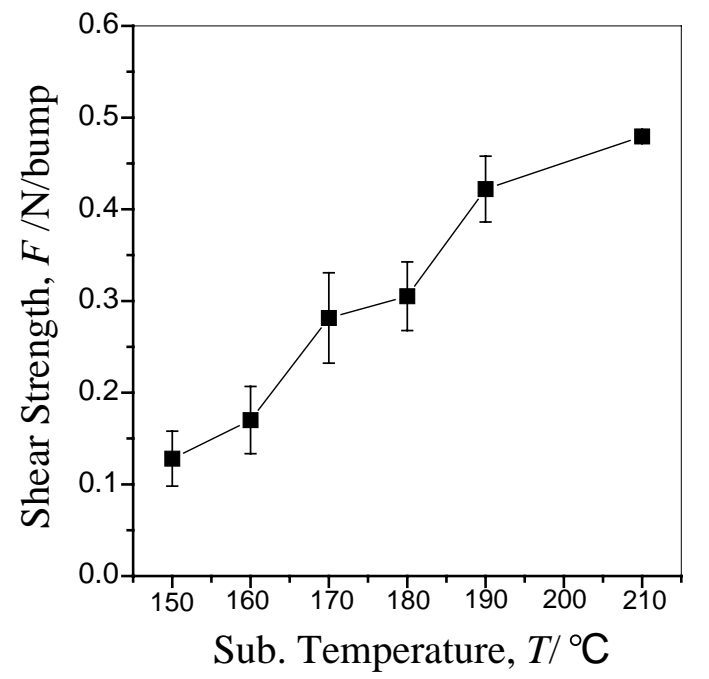

Fig. 4 Shear strength per bump from die shear test of ultrasonically bonded $\mathrm{Sn}-3.5$ masst\% Ag bumped die with bonding temperature. (The bonding load is $0.8 \mathrm{~N} /$ bump. The ultrasonic power is $25 \mathrm{~W}$ ).

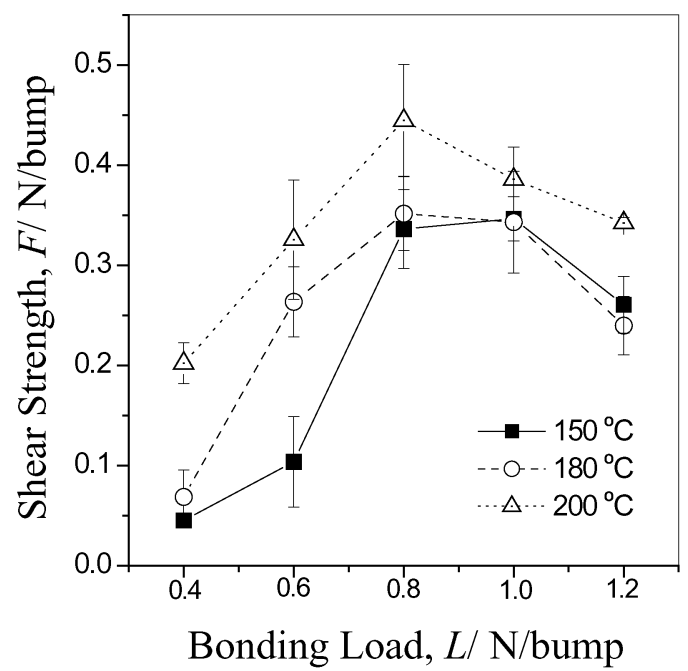

Fig. 5 Shear strength per bump from die shear test of ultrasonically bonded Sn-3.5 mass\% Ag bumped die with bonding load. (The ultrasonic power is $25 \mathrm{~W})$.

tures, the die shear strength increased as high as $0.5 \mathrm{~N}$ to the bonding load of $0.8 \mathrm{~N} / \mathrm{bump}$ but decreased above $1.0 \mathrm{~N} / \mathrm{bump}$.

The principle of the ultrasonic bonding is known to be similar to friction bonding. That is, the ultrasonic wave shakes strongly the chip and substrate that are contacted with each other by bonding load. Through friction, the oxide or surface contaminants at the interface between solder bump and TSM are removed and the pure solder and TSM metal layers are bonded. ${ }^{16)}$ Therefore, some amount of bonding load is essential to generate the friction of two bodies. The excessive bonding load, however, will suppress the amplitude of ultrasonic vibration, that is, the relative movement of two bodies, so that the shear strength of the die is reduced. In a few researches on the thermosonic bonding of Au bump, it has been reported that the vibration amplitude at the ultrasonic horn tip decreased with increasing load. ${ }^{10,13)}$

After die shear test, fracture surfaces were examined with SEM. The fracture surfaces were classified into three categories as shown schematically in Fig. 6. Mode A is the frac-
Mode A

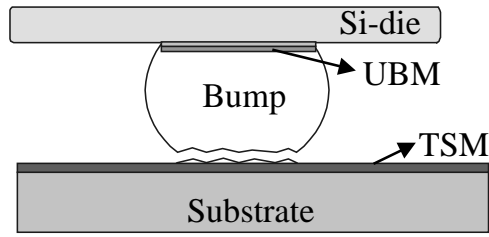

(a)

Mode B

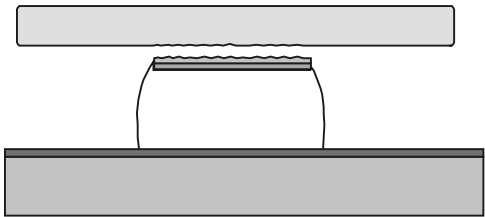

(b)

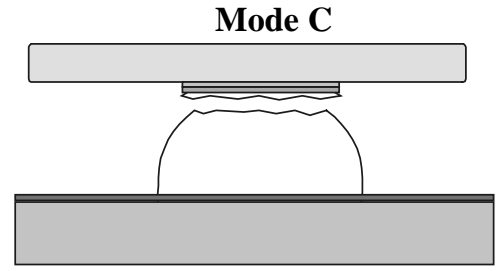

(c)

Fig. 6 Fracture modes of the die shear test specimen. (a) Interface between solder and TSM of glass substrate. (b) Interface between UBM and Si-wafer. (c) Interface between solder and UBM of Si-wafer.

ture between solder and TSM of glass substrate and indicates insufficient bond strength between solder and TSM. Mode $B$ is the fracture at the interface between UBM and Si-die and mode $\mathrm{C}$ is the fracture at the interface between solder and UBM of Si-die. Mode B or Mode C fracture reflects sound bonding between solder and TSM. Mode B or Mode $\mathrm{C}$ fracture reflects that the bonding between solder and TSM is sound. Mode B and C are determined by the bond strength of the UBM/Si-wafer and solder/UBM interface.

The Fig. 7 shows fracture surfaces of die-side at different load and temperature condition. The fracture mode changed from mode A to mode B with increasing bonding load and temperature. At the bonding load condition of $1.2 \mathrm{~N} / \mathrm{bump}$, the fracture mode was B as was the same fracture mode at $0.8 \mathrm{~N} /$ bump. However, the die shear strength was lower. Therefore, although the decrease in die shear strength over bonding load of $0.8 \mathrm{~N} /$ bump was explained by the vibration amplitude decrease in the previous paragraph, the possibility cannot be excluded that the ultrasonic vibration weakened the bond strength between UBM and Si-die.

Figure 8 displays the die shear strength variation with ultrasonic power, which means that strong friction improved the bond strength. The die shear strength increased with increase in ultrasonic power. Figure 9 shows the bump height according to the bonding load. The initial bump height was about $70 \mu \mathrm{m}$. The bump height decreased with increasing bonding load. Most underfill materials require at least a $25 \mu \mathrm{m}$ gap between the chip and the substrate. ${ }^{17)}$ Therefore, at bonding temperature of $180^{\circ} \mathrm{C}$, the load should be below $0.8 \mathrm{~N} / \mathrm{bump}$, if underfill is considered after flip chip bonding.

The ultrasonic bonding of solder flip chip is expected as one of the fluxless flip chip bonding methods. Especially, 


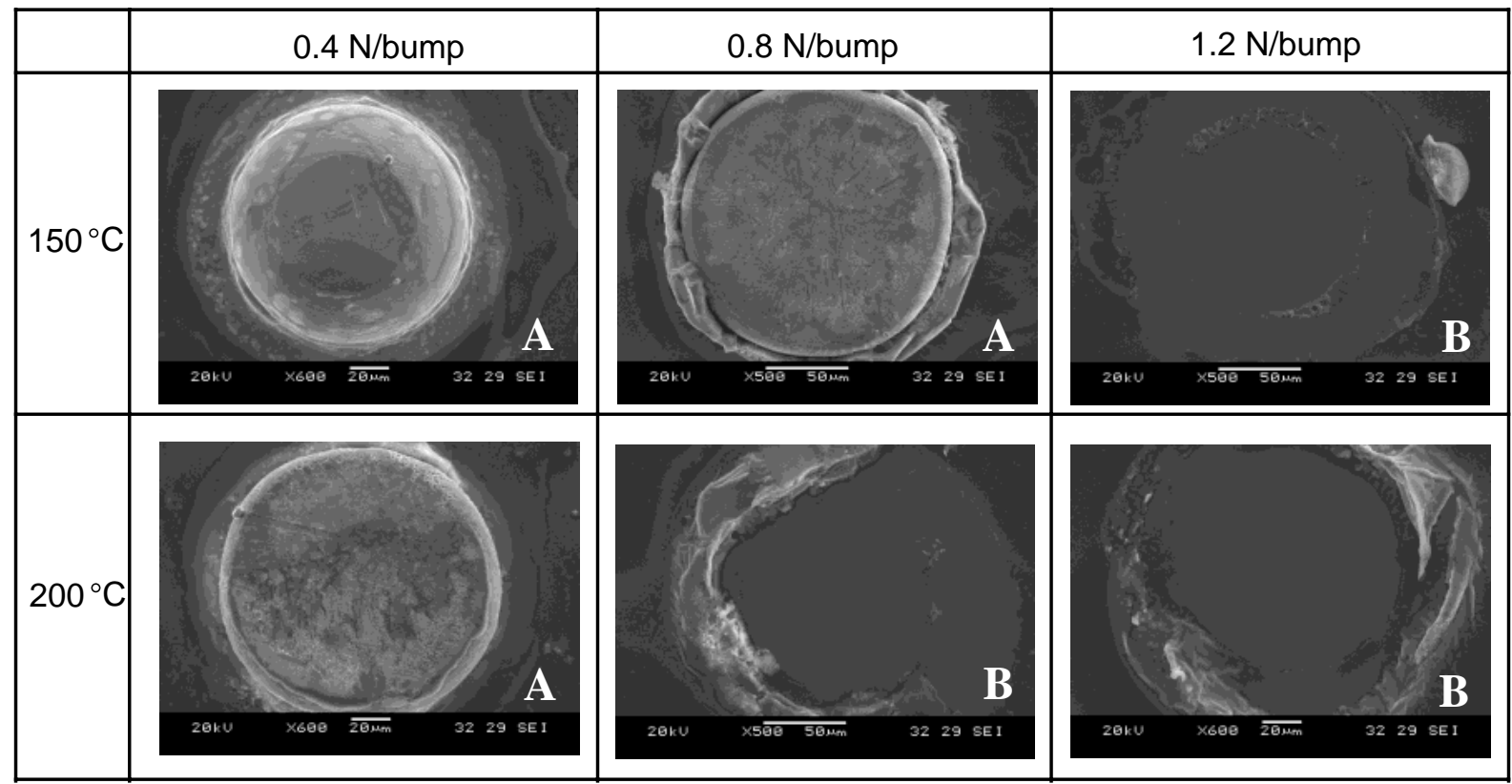

Fig. 7 Fracture surfaces of the ultrasonically boned Sn-3.5 mass\%Ag bump flip chip with different bonding condition. (Die Side).

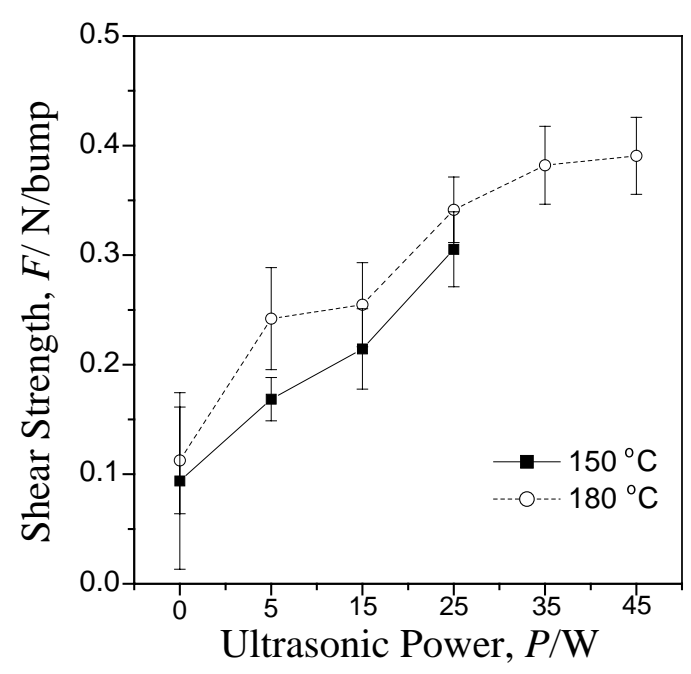

Fig. 8 Shear strength per bump from die shear test of ultrasonically bonded $\mathrm{Sn}-3.5 \mathrm{wt} \% \mathrm{Ag}$ bumped die with ultrasonic power. (The bonding load is $0.8 \mathrm{~N} /$ bump).

there are many $\mathrm{Sn}$-base $\mathrm{Pb}$-free solders having higher melting point than that of eutectic $\mathrm{Sn}-\mathrm{Pb}$ solder. Their operating temperatures are $30-40^{\circ} \mathrm{C}$ higher than that of $\mathrm{Sn}-\mathrm{Pb}$ solder. Higher operating temperatures may have a negative effect on component performance, and on the component ratings. Therefore, if a solder flip chip device is sensitive to high operation temperature, ultrasonic bonding can be useful to attach the chip to substrate at low temperature. However, in ultrasonic flip chip bonding, self-alignment dose not occur since the solder bump is not heated above melting point. Thus, assembly and attachment requires more precise placement to complete the process. This problem will be solved by the development of the flip chip aligning and placing equipment.

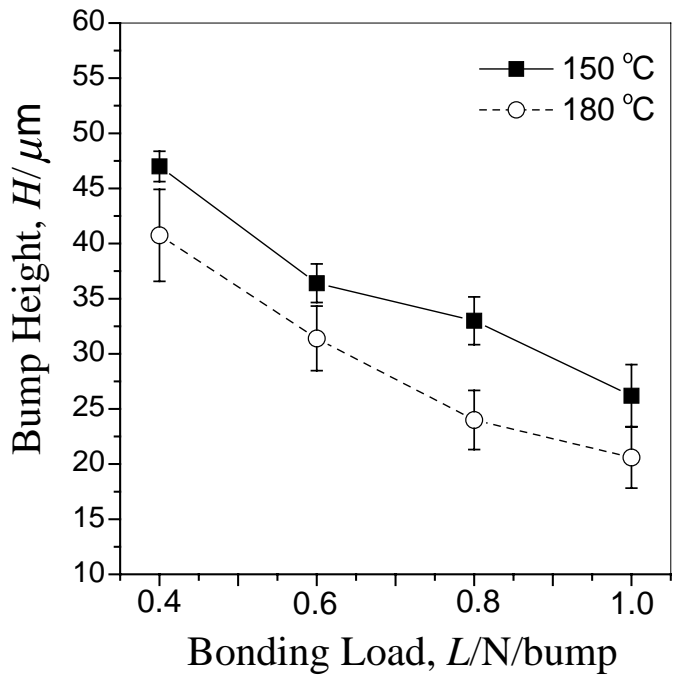

Fig. 9 Sn-3.5 mass\%Ag solder bump height after ultrasonic bonding with different bonding load. (The ultrasonic power is $25 \mathrm{~W}$ ).

\section{Conclusion}

By ultrasonic bonding, the Sn-3.5 mass\%Ag solder flip chip bonding was possible at lower temperature than the melting point of the solder. The die shear strength increased with increase in substrate temperature, bonding load, and ultrasonic power. However, at excessive loading condition over $0.8 \mathrm{~N} /$ bump, the die shear strength decreased. The bump height decreased with increasing bonding load. The fluxless flip chip bonding using ultrasonic wave is expected to solve the problem of high reflow temperature of some $\mathrm{Pb}$-free solders to be applied to temperature sensitive flip chip devices which does not require the self-alignment. 


\section{REFERENCES}

1) R. R. Tummala: Fundamentals of Microsystems Packaging, (McGrowHill, New York, 2000) p. 544

2) C. Beddingfield and L. M. Higgins: IEEE Trans. on CPMT Part C, 21 (1998) 189-195.

3) M. Bixenaman and E. Miller: Pro. 5th Int. Joint Symp. on Microelec. and Packaging, (IMAPS-KOREA and IEEE-CPMT, Seoul, Korea) (2000) pp. 43-55.

4) K. J. Wolter, Th. Zerna, R. Deltschew and H. Neumann: 2001 IEEEETCT Conference Proceeding, (2001) pp. 1295-1298.

5) N. Koopman, S. Bobbio, S. Nangalia, J. Bousaba and B. Piekarski: 1993 IEEE-ECTC Conference Proceeding, (1993) pp. 595-605.

6) H. Matsuki, H. Matsui and E. Watanabe: Proceeding of 2001 Intl Symposium on Advanced Packaging Materials, (2001) pp. 135-139.

7) F. Masahiko, M. Tsugunori, D. Kazuhide and N. Hiroshi: 1999 IEEEECTC Conference Proceeding, (1999) pp. 408-414.

8) H. R. Faridi, J. H. Devletian and H. P. Le: Welding Journal September, (2000) pp. 41-45.

9) S. Y. Kang, P. M. Williams, T. S. McLaren and Y. C. Lee: Mater. Chem.
Phys. 42 (1995) 31-37.

10) S. Y. Kang, P. M. Williams and Y. C. Lee: IEEE Trans. CPMT, Part B, 18, No. 4 (1995) 728-733.

11) Q. Tan, W. Zhang, B. Schaible and L. J. Bond: IEEE Trans. CPMT, Part B, 21, No. 1 (1998) pp. 53-58.

12) T. Tomioka, I. Mori and K. Atsumi: Proceeding of 6th Symposium on Microjoining and Assembly Technology in Electronics, (2000) pp. 163-168.

13) M. Hashimoto, T. Yonezawa and K. Higashi: Proceeding of 6th Symposium on Microjoining and Assembly Technology in Electronics, (2000) $175-178$.

14) R. Kajiwara, M. Koizumi and T. Morita: Proceeding of 7th Symposium on Microjoining and Assembly Technology in Electronics, (2001) pp. 161-166.

15) NCMS: NCMS Lead-Free Solder Project, SMTs Guide to Lead-free Soldering, June (2000) pp. 3-8.

16) J. E. Krzanowski: IEEE Trans. CPMT, Vol. 13, No. 1 (1990) 176-181.

17) J. H. Lau ed.: Flip Chip Technologies, (McGraw-Hill, New York, 1995) p. 134. 